\title{
Project ID \#95016. Aluminum-Containing Phases in Tank Waste: Precipitation and Deposition of Aluminum-Containing Phases
}

Principal Investigator: Shas Mattigod, Pacific Northwest National Laboratory, MS K6-81, Richland, WA 99352; Phone: (509) 376-4311; E-mail: shas.mattigod@pnl.gov. Co-Investigators: D. T. Hobbs (david.hobbs@srs.gov, 803-725-2838) Savannah River National Laboratory; D. M. Wellman (dawn.wellman@pnl.gov, 509-375-2017), Pacific Northwest National Laboratory; I. Aksay (1aksay@princeton.edu, 609-258-4393) and D. M. Dabbs (dabbs@princeton.edu, 609-2581572), Princeton University.

\section{Research Objective}

Aluminisilicate deposit buildup experienced during the tank waste volume-reduction process at the Savannah River Site (SRS) required an evaporator to be shut down in October 1999. Recent investigations illustrated the accumulation $7 \mathrm{wt} \%$ uranium, $3 \%$ was ${ }^{235} \mathrm{U}$ and absent of neutron poisons, within these deposits and presented a criticality concern. The Waste Processing Technology Section of Westinghouse Savannah River Company at SRS is now collaborating with a team from Pacific Northwest National Laboratory in efforts to identify the phases controlling uranium solubility and understand the conditions under which they precipitate.

The objective of this project is to: 1) identify the insoluble uranium phase(s) and characterize the chemistry and microstructure of these phases, 2) study the kinetics of the phase formation and transformation of uranium phases under hydrothermal conditions, and 3) verify the stability boundaries in the activity diagram of interest to the $2 \mathrm{H}$ Evaporator, namely the critical concentrations for formation of uranyl-hydroxide versus uranyl-silicate phases. This research is critical to understand the mechanism for incorporating uranium phases into the sodium-aluminosilicate (NAS) scales and inhibit the growth of NAS scales. Prevention of enriched uranium phases within the evaporator scales, will minimize criticality concerns, and will increase waste stream processing flexibility.

\section{Research Progress and Implications}

This report summarizes work completed after two years of a three year project.

\section{Formation of Uranium Solids Under Evaporator Relevant Conditions}

A detailed, systematic study has been initiated to investigate the formation and solubility of uranium solid phases under conditions relevant to the SRS evaporators. A set of batch experiments have been conducted in the complex Na-Si-Al- $\mathrm{UO}_{2}{ }^{2+}-\mathrm{H}_{2} \mathrm{O}$ system to discern the formation of uranium minerals in the presence of high sodium and silicon (Table 1). Because aluminum has previously been shown to have little or no effect on uranium precipitation, a fixed aluminum concentration was used for all experiments. Additionally, under alkaline conditions the effect of nitrate on uranium chemistry is minimal; therefore, the concentration of nitrate was fixed. The newly operating $3 \mathrm{H}$ evaporator involves the evaporation of wastes with significantly higher uranium enrichment. The uranium concentration was fixed to an upper bounding concentration limit based on maximum concentration measured in $2 \mathrm{H}$ evaporator samples. Concentrations of sodium, silicon, and hydroxide were varied under alkaline conditions and as a function of temperature to evaluate the effects of solution composition and temperature $\left(40\right.$ to $\left.175^{\circ} \mathrm{C}\right)$ on uranium phase formation under conditions and within concentration ranges typically encountered within the evaporators. 
Table 1. Uranium Phase Formation Test Solution Compositions

\begin{tabular}{|c|c|c|c|c|c|c|c|}
\hline Solution No. & $\mathbf{U}(\mathbf{M})$ & $\mathbf{N a}(\mathbf{M})$ & $\mathbf{S i}(\mathbf{M})$ & $\mathbf{A l}(\mathbf{M})$ & $\mathbf{N O}_{3}{ }^{-} \mathbf{( M )}$ & $\mathbf{O H}^{-}(\mathbf{M})$ & $\mathbf{C O}_{3}{ }^{-}(\mathbf{M})$ \\
\hline 1 & 0.1 & 3.28 & 0.005 & 0.01 & 3.0 & 0.1 & 0.2 \\
2 & 0.1 & 3.37 & 0.05 & 0.01 & 3.0 & 0.1 & 0.2 \\
3 & 0.1 & 4.18 & 0.005 & 0.01 & 3.0 & 1.0 & 0.2 \\
4 & 0.1 & 4.27 & 0.05 & 0.01 & 3.0 & 1.0 & 0.2 \\
5 & 0.1 & 8.18 & 0.005 & 0.01 & 3.0 & 5.0 & 0.2 \\
6 & 0.1 & 8.27 & 0.05 & 0.01 & 3.0 & 5.0 & 0.2 \\
7 & 0.1 & 3.29 & 0.01 & 0.01 & 3.0 & 0.1 & 0.2 \\
8 & 0.1 & 4.19 & 0.01 & 0.01 & 3.0 & 1.0 & 0.2 \\
9 & 0.1 & 8.19 & 0.01 & 0.01 & 3.0 & 5.0 & 0.2 \\
10 & 0.1 & 1.81 & 0.005 & 0.5 & 3.0 & 0.1 & 0.2 \\
11 & 0.1 & 1.90 & 0.05 & 0.5 & 3.0 & 0.1 & 0.2 \\
12 & 0.1 & 2.71 & 0.005 & 0.5 & 3.0 & 1.0 & 0.2 \\
\hline \multicolumn{7}{|c|}{ Reaction Temperatures 40,80, and $175^{\circ} \mathrm{C}$} \\
\hline
\end{tabular}

The reactions were carried out over varying periods of time to study the initial precipitation and the crystallization and transformation processes. The duration of the experiments, 3 months, is representative of the residence time within the SRS evaporator. The samples are filtered hot and quenched into acid in order to determine the soluble components. Solid samples are characterized using chemical digestion followed by ICP-MS and ICP-OES analyses, SEM-EDS, and X-ray diffraction, to evaluate formation and transformation of uranium-bearing solid phases under evaporator conditions.

Figure 1 displays XRD patterns obtained from solids which formed instantaneously upon mixing test solutions. Diffraction patterns indicate all solids are amorphous; however, solution 3, 5, 6, 8, and 9 display broad peaks centered at $\sim 15$ and $28^{\circ} 2 \theta$. Due to the complex matrix and limited structural definition, the composition of the amorphous solid phases could not be defined via XRD.

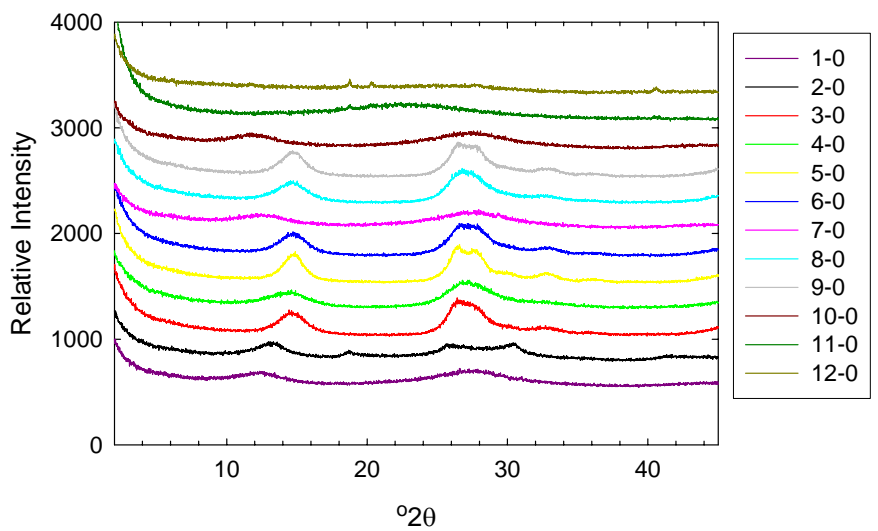

Figure 2 displays XRD patterns obtained Figure 1. X-Ray diffraction patterns from initial from solid phases formed with in test solutions at $40^{\circ} \mathrm{C}$ after 4,48 , and $1440 \mathrm{hrs}$. Results indicate that given a reaction interval of 4 hours at $40^{\circ} \mathrm{C}$, the solid phases are amorphous in all compositions except solution composition \#10. The precipitate from solution \#10 was consistent with PDF\#08-0096 for bayerite, $\mathrm{Al}_{2} \mathrm{O}_{3} \cdot x \mathrm{H}_{2} \mathrm{O}$. Additionally, the broad amorphous peaks centered $\sim 15^{\circ}$ and $28^{\circ} 2 \theta$ in solutions $3,5,6,8$, and 9 are still evident and give no appearance of further structural definition. Increasing the reaction time from 4 to 48 hours, however, begins to suggest further structural definition solids formed from solutions 3, 5, 6, 8, and 9. The intensity of the peaks centered at $\sim 15^{\circ}$ and $28^{\circ} 2 \theta$ increased and the broad peaks displayed at $\sim 28^{\circ} 2 \theta$ is suggesting two peaks may be present within this region for solids precipitated from solution 3, 5, and 9 . Furthermore, the precipitate obtained from solution 12 appears highly crystalline. Pattern fitting suggests the solid is consistent with a mixed phase precipitate containing uranyl carbonate (PDF\# 34-0578), sodium uranyl carbonate (PDF\#13-0038), sodium uranyl oxyhydroxide (PDF\# 
53-0876). There is no apparent difference in the structural definition of solids formed from solutions 2-6, 8-11 given a reaction period of 1440 hours. Additionally, the structure of the precipitate obtained from solution \#12 remains consistent with that observed after $48 \mathrm{hrs}$, a mixed phase precipitate containing uranyl carbonate (PDF\# 34-0578), sodium uranyl carbonate (PDF\#130038), sodium uranyl

oxyhydroxide (PDF\# 53-0876). However, the solid phases formed from solutions \#1 and 7 began to exhibit a limited degree of structural definition which is comparable between the two solids. However, in fitting the pattern to the XRD database, there are no known minerals, or combinations therein, that accurately match the diffraction pattern. Further investigation is necessary to define the composition of this precipitate.

Increasing the reaction temperature to $80^{\circ} \mathrm{C}$ (Figure 3) revealed the rapid formation of amorphous solid phases in all compositions after only 4 hours, except compositions 10 and 11 which did not display solid phase formation through the duration of the test. As noted for the amorphous phases formed at $40^{\circ} \mathrm{C}$, broad peaks were centered at peaks centered at $\sim 15^{\circ}$ and $28^{\circ} 2 \theta$. Additionally, the precipitate obtained from solution \#12 after only 4 hours displayed a diffraction pattern consistent with that observed at 40 degrees after 48 hours. Increasing the reaction period to 48 hours had little effect on solids formed from solutions 2-6, 8-12. However, the precipitates formed within solutions \#1 and 7 displayed a sharp increase in crystallinity. The diffraction patterns are consistent with PDF\# 51-1474, $\mathrm{Na}_{4}\left(\mathrm{UO}_{2}\right)\left(\mathrm{CO}_{3}\right)_{3}$.
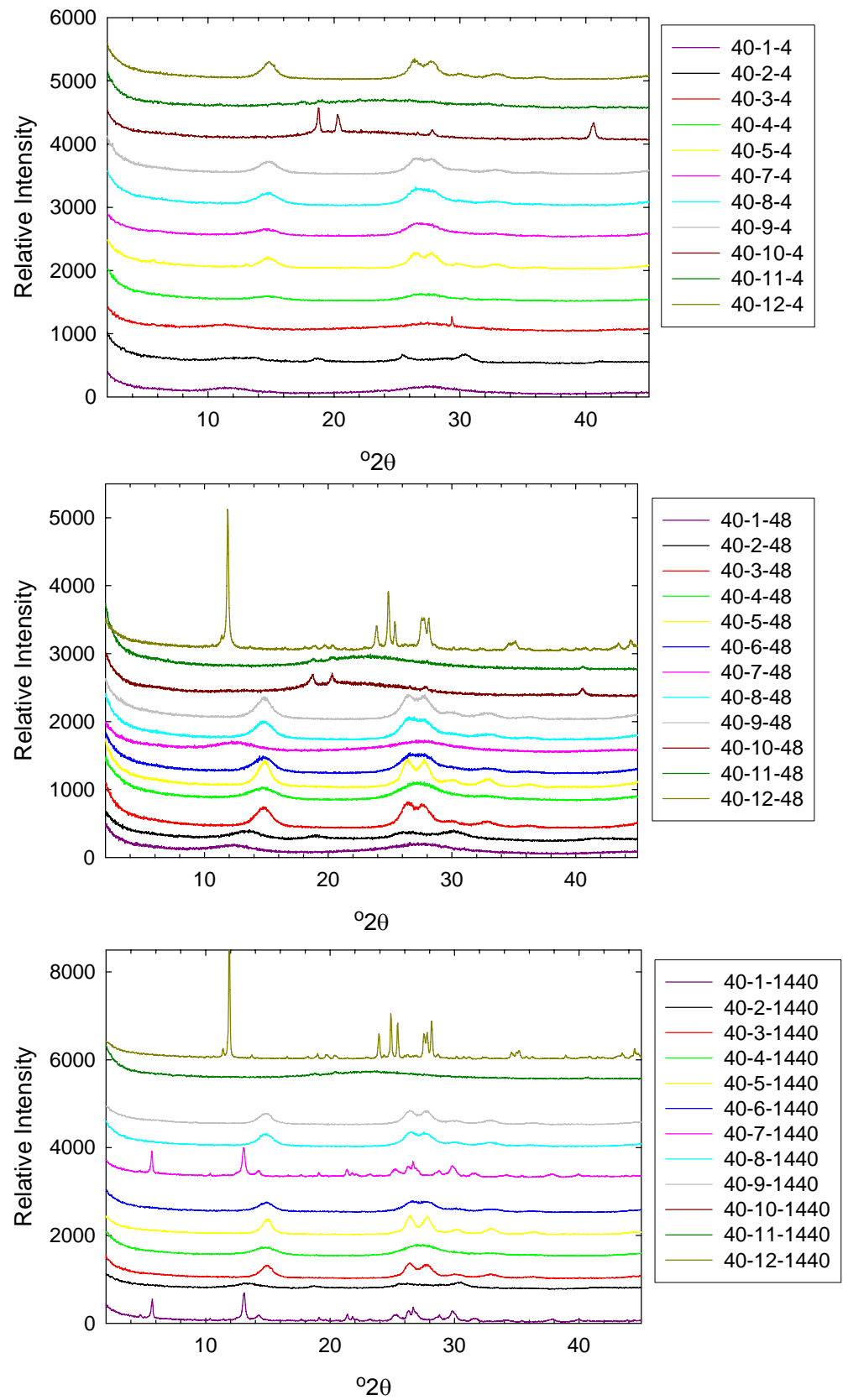

Figure 2. X-Ray diffraction patterns from uranium phase formation test solutions at $40^{\circ} \mathrm{C}$ after 4,168 , and $1440 \mathrm{hrs}$ (top to bottom). 
Conducting experiment under conditions relevant to those encountered within the evaporators, $175^{\circ} \mathrm{C}$, revealed a pronounced effect on the degree of crystallinity and rate within which it was obtained for precipitates in all solution compositions. Figure 4 displays diffraction patterns of precipitates produced within the first four hours. Results indicate that precipitates produced from all solutions were crystalline within the initial fours hours. Further heating at $175^{\circ} \mathrm{C}$ elicited change in the crystalline structures of the precipitates from solution \#10-12. However, the degree of crystallinity and structure of all other precipitates remained constant through 720 hours at $175^{\circ} \mathrm{C}$. Solutions \#1 and 2 produced identical precipitates, which were consistent with PDF\# 11-0081, $\mathrm{Na}_{4}\left(\mathrm{UO}_{2}\right)\left(\mathrm{CO}_{3}\right)_{3}$. Precipitates from
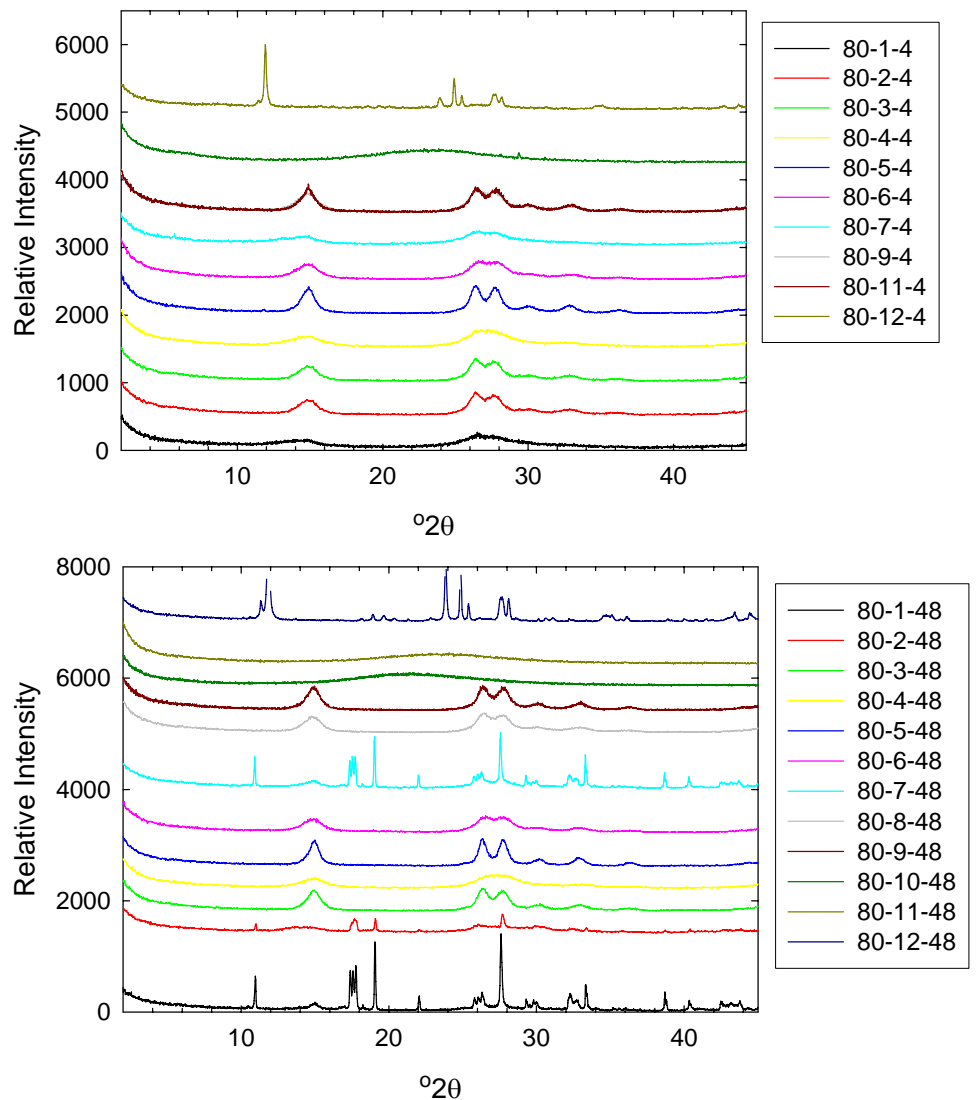

Figure 3. X-Ray diffraction patterns from uranium phase formation test solutions at $80^{\circ} \mathrm{C}$ after 4 (top) and 48 (bottom). solutions \#3-6, 8-9 were also identical in composition and consistent with sodium uranyl oxyhydroxide (PDF\# 53-0876). Precipitates from solutions 10 and 11 were produced identical diffraction patterns; however, the precipitate in solution 11 exhibited less crystallinity than that produced within solution 10 . The precipitate from solution 12 was highly crystalline after 4 hours and consistent with nitratine, $\mathrm{NaNO}_{3}$ (PDF\# 85-0850). The precipitate remained stable through 24 hours; however, at 48 hours the broadening of peaks and transformation to alternative crystalline structures was evident. At 720 hours the diffraction pattern for the precipitate from solution 12 exhibited a single low angle peak with no definite structure or composition identifiable via XRD.

Programmatic limitations have hindered quantification of aqueous concentration which would allow completion of mass balance calculations and identification of correlations between aqueous concentration and solid phase formation. Results of solid phase analyses via XRD indicate that under conditions comparable to waste within the SRS evaporator system:

1. There is little detectable precipitation at low hydroxide (i.e. $0.1 \mathrm{M}$ ) and low sodium concentrations (i.e. $<2.0 \mathrm{M}$ ).

2. Composition of uranium solid phases is dominated by the formation of uranium carbonates with and without the incorporation of sodium.

3. Comparison of results from solutions 1 and 2, 3 and 4, 5 and 6 suggest high silica concentrations, $\geq 0.05 \mathrm{M}$, may inhibit the formation of uranium carbonates. Additionally, X- 
ray diffraction results do not suggest the formation of any secondary crystalline uraniumsilicate phases under test conditions.

4. There is no indication aluminum is incorporated into any of the uranium phases; however, high aluminum concentrations, $\geq 0.5 \mathrm{M}$, may inhibit the formation of uranium -bearing solid phases.

Results presented here support findings by Duff et al. (2004) who characterized an archived sample from the $2 \mathrm{H}$ evaporator. Duff et al. characterized scale from the $2 \mathrm{H}$ evaporator using a suite of analytical techniques including mass spectrometry, XRD, scanning electron microscopy (SEM), XAFS, $\mathrm{X}$-ray absorption near-edge structure (XANES) and extended X-ray absorption fine structure (EXAFS). The results of this investigation provided new in-sight into the method of uranium concentration within the evaporator. XRD identified sodium uranyl-carbonates as a dominant crystalline uranium phase. However, SEM studies indicated the presence of uranium in two differing morphologies of sodium/silicon/aluminum, one-being uranium rich with minor amounts of sodium/silicon/aluminum, the other being a sodium/silicon/aluminum phase with minor amounts of uranium. There was no evidence from results present here that uranium was associated with any sodium/silicon/aluminum phases. However, evaporator processes allow scale to accumulate on the walls
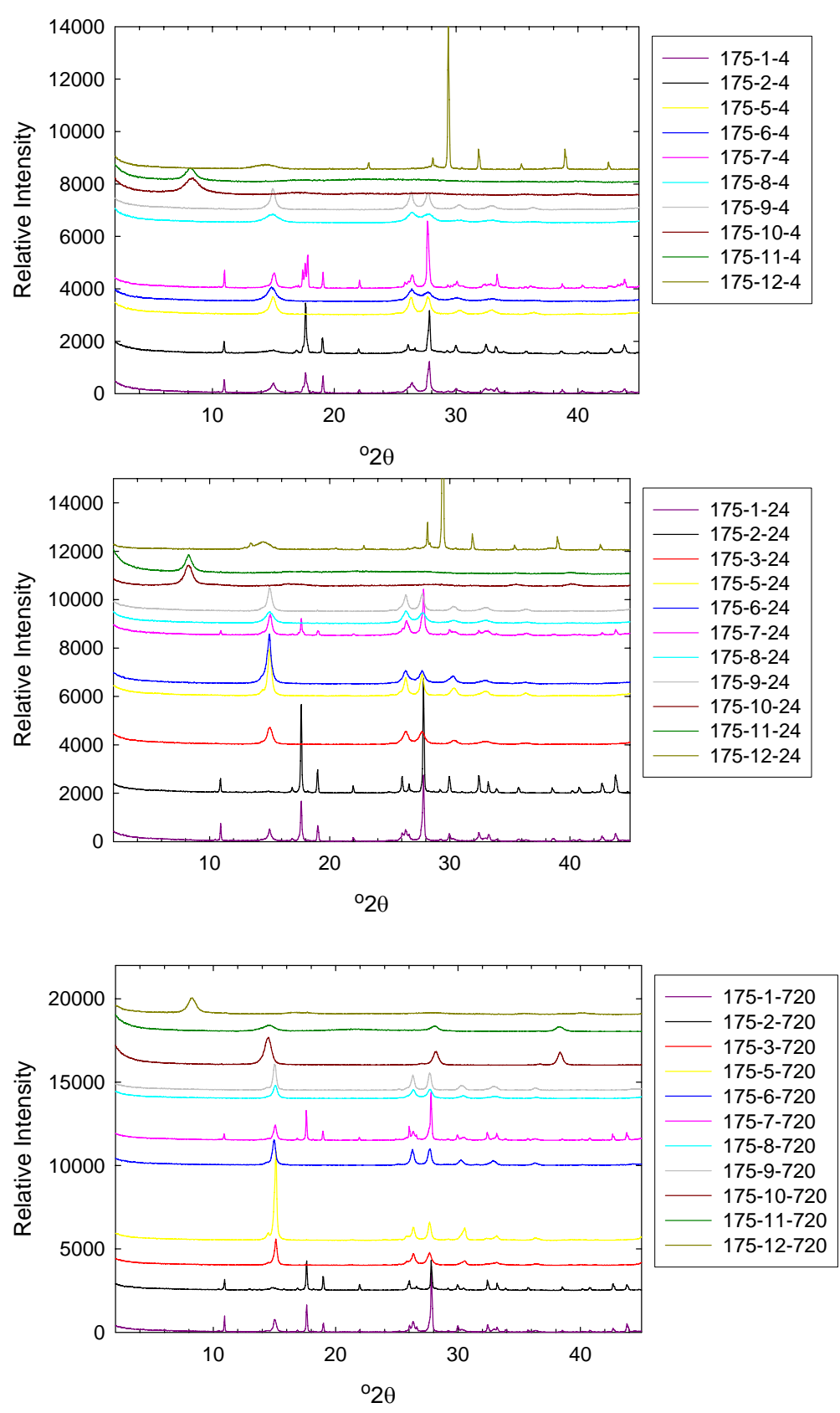

Figure 4. X-Ray diffraction patterns from uranium phase formation test solutions at $40^{\circ} \mathrm{C}$ after $4,24,48$, and $720 \mathrm{hrs}$ (top to bottom). 
within the evaporator. In contrast, tests conducted here were completed in Teflon lined Parr reactors to evaluate precipitates forming directly from solution. It is highly possible the precipitation of sodium aluminosilicates previous quantified under evaporator conditions may serve as sorptive surfaces for the accumulation of uranium and should be considered in future investigations.

\section{Information Access}

\section{Publications}

Wellman, D.M., K. E. Parker, C. Iovin, I. V. Kutnyakov, M.M. Valenta, S. V. Mattigod, and D T. Hobbs. In progress. "Precipitation and deposition of uranium-bearing phases in tank wastes".

Mattigod, S. V., D T. Hobbs, K. E. Parker, D. E. McCready, L. Q. Wang. 2006. "Effects of Sodium Hydroxide and Sodium Aluminate on the Precipitation of Aluminum containing Species in Tank Wastes". In Nuclear Waste Management: Accomplishments of the Environmental Management Science Program. Eds P. Wong and T. Zachry. American Chemical Society, Washington DC.

Wang, L. Q. S. V. Mattigod, K. E. Parker, D. T. Hobbs and D. E. McCready 2005. "Nuclear magnetic resonance studies of aluminosilicate gels prepared in high-alkaline and salt-concentrated solutions" $J$. Non-Crystalline Solids, V. 351, No 43-45, 3435-3442

Gong, XY, Nie ZM, Qian, MX, Liu, J., Pederson, LA, Hobbs DT, McDuffie NG. 2003. Gobbsite to boehmite transformation in strongly caustic and nitrate environemtns. Ind. \& Eng. Chem. Res. 42(10): 2163-2170

\section{Presentations}

Mattigod, SV., Hobbs, DT. KE Parker, DE McCready, and LQ Wang. 2004. Precipitation of scaleforming species during processing of high level wastes. ACS meeting 227.

Mattigod, SV., Hobbs, DT. KE Parker, DE McCready, and LQ Wang. 2003. Precipitation of Aluminum containing species in tank wastes. ACS meeting 226.

Mattigod, SV., L. Wang, DT. Hobbs, D. Dabbs, and I. Aksay. 2001. "Precipitation and Deposition of Aluminum-Containing Phases in tank Wastes" EMSP Workshop, Richland, WA. November 7-8, 2001.

Mattigod, SV., Hobbs, DT, Parker, KE, Nie, Z and D. McCready 2001. "Precipitation of aluminum containing species in tank wastes" Zeolite Workshop, Aiken, SC June 7, 2001.

Hobbs, DT Mattigod, SV., J. Liu, Z. Nie, 2001. "Formation of Aluminosilicate Phases Pertinent to the Evaporation of High-Level Nuclear Wastes" ACS Meeting, Chicago, Illinois August 26- 30, 2001.

Mattigod, SV., L Wang, DT Hobbs, D. Dabbs, and I. Aksay. 2001. "Precipitation and Deposition of Aluminum-Containing Phases in tank Wastes" EMSP Workshop, Richland, WA. November 7-8, 2001. 